\title{
Performance of cement stabilized recycled aggregate base course added with metakaolin
}

\author{
Jianming $\mathrm{Yao}^{1}$, Wei Wang ${ }^{2}$, and Xuyan Song ${ }^{3, *}$ \\ ${ }^{1}$ Suzhou Transport Investment Planning Design and Management Co., Ltd., 215000, China \\ ${ }^{2}$ School of Civil Engineering,Chongqing Jiaotong University,Chongqing 400074,China \\ ${ }^{3}$ Road Engineering Research Center, Suzhou University of Science and Technology, 215000, China
}

\begin{abstract}
In order to better use the old cement concrete pavement materials in the cement stabilized base of the reconstruction or new road. In this paper, metakaolin was used to replace recycled fine aggregate with different proportions to prepare cement stabilized recycled aggregate base mixture, and the physical and mechanical properties and dry shrinkage properties of cement stabilized recycled aggregate base mixture were studied. The results of the study show that adding a proper amount of metakaolin can reduce the optimal water content of the mixture, increases the maximum dry density and $7 \mathrm{~d}$ unconfined compressive strength of the mixture, and also reduces the total water loss and dry shrinkage of the mixture. The research results can provide new ideas for the recycling of road waste materials.
\end{abstract}

Keywords: Metakaolin; Recycled aggregate; Strength; Dry shrinkage.

\section{Introduction}

Since the 40 years of reform and opening up, China has devoted all its manpower and material resources to civil engineering and greatly improved the quantity and quality of infrastructure. The vigorous development of road traffic and transportation projects has contributed to China's economic take-off. In the early and middle stages of this construction process, most roads use cement concrete as road surface layer. After years of vehicle load and natural factors, many urban roads have been damaged to varying degrees. The process of road reconstruction or expansion will produce a large number of waste solid waste, disposal of these wastes need to spend a lot of money and manpower, adversely affect the surrounding environment of the city[1].

Cement stabilized base is a kind of base structure widely used in road in China because of its high stiffness, low cost and good construction performance. The thickness of the structural layer of the base material is generally large, which requires more sand and stone materials. Therefore, the application of solid waste as recycled aggregate in cement stabilized base is one of the best ways to realize the reuse of solid waste, which not only saves costs, but also has the effect of protecting the environment $[2,3]$. However, due to the large amount of cement paste contained in recycled aggregate and the micro-cracks

\footnotetext{
*Corresponding author: songxuyan2002@163.com
} 
generated in the crushing process, the water absorption rate increased, the mechanical properties decreased, and the cracks were prone to dry shrinkage, which further led to the occurrence of pavement reflection cracks in the service process.

Metakaolin is a mineral admixture made by calcining kaolin. It contains a large amount of amorphous silicon dioxide and aluminum oxide. It has high pozzolanic activity and the function of filling the gap of cement paste, which can improve the mechanical properties of concrete significantly reduce its internal porosity [4-5]. Wang Chong et al. [6] showed that adding 5\% metakaolin to concrete can significantly reduce the shrinkage of concrete, and the shrinkage of concrete has a great relationship with the content of metakaolin. In order to explore whether metakaolin can improve the mechanical properties and drying shrinkage performance of cement stabilized recycled aggregate base, metakaolin was added to cement stabilized recycled aggregate base mixture with different contents, and the changes of physical and mechanical properties and drying shrinkage performance were studied.

\section{Raw materials and test methods}

\subsection{Raw material}

Aggregate: The recycled aggregate used in this experiment was taken from the pavement recycling material of a highway in Jiangsu. It is divided into recycled coarse material $(10 \sim 26 \mathrm{~mm})$, recycled medium material $(5 \sim 10 \mathrm{~mm})$ and recycled fine material $(0 \sim 5 \mathrm{~mm})$. The apparent densities were $2.62 \mathrm{~g} / \mathrm{cm}^{3}, 2.65 \mathrm{~g} / \mathrm{cm}^{3}$ and $2.81 \mathrm{~g} / \mathrm{cm}^{3}$, respectively. The water absorption rates were $5.28 \%, 8.09 \%$ and $10.1 \%$, respectively. The crushing value was 24.5 , the needle content was $6.0 \%$, and the mud content was $0.7 \%$. In order to analyze and study the composition and surface morphology of recycled aggregate, XRD and SEM were used to observe the recycled aggregate. The diffraction pattern and microstructure are shown in Fig. 1 and Fig.2.

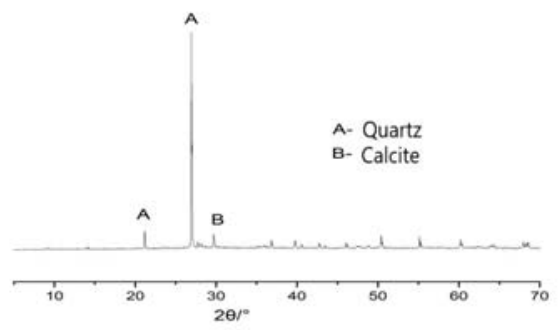

Fig. 1. XRD diffraction pattern of recycled aggregate.
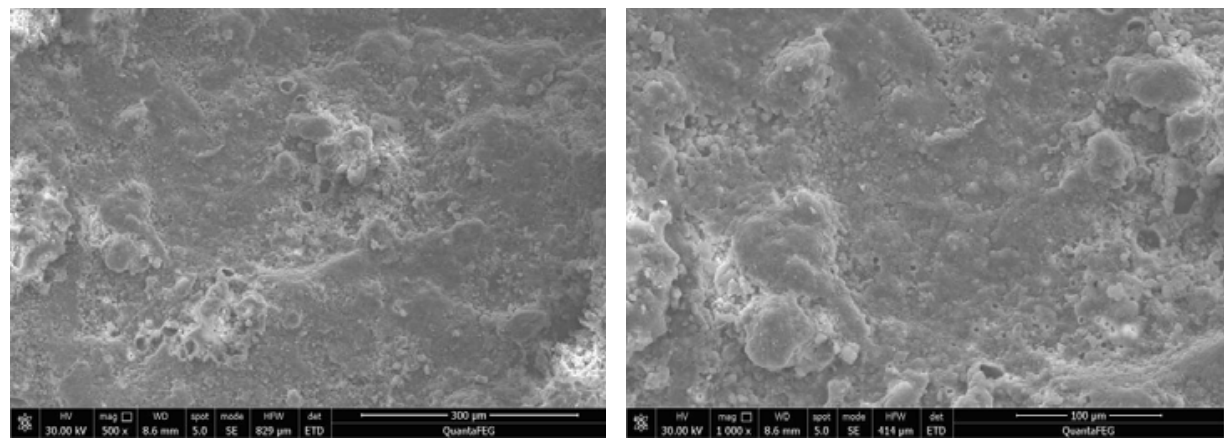

Fig. 2. SEM of recycled aggregate. 
It can be seen from the above spectra that the main components are quartz $\left(\mathrm{SiO}_{2}\right)$ and calcite $\left(\mathrm{CaCO}_{3}\right)$, and the quartz content in aggregate is the highest. It can be seen from the SEM diagram that the grain size of recycled aggregate is different, the surface is rough, and a large number of hydration products such as cement mortar are covered. The porous interface proves that recycled aggregate has high water absorption. In addition, obvious microcracks can be observed on its surface, which may adversely affect its strength.

The cementitious material is Tianshan PO42.5 cement produced by Suzhou Damin Building Materials Co., Ltd. Metakaolin is produced by Henan Jiaozuo Yukun Mining Co., Ltd. Chemical composition is shown in Table 1; the mixing water is Suzhou municipal drinking water.

Table 1. Chemical composition of metakaolin.

\begin{tabular}{|c|c|c|c|c|c|c|c|}
\hline $\mathrm{Sio}_{2}(\%)$ & $\mathrm{Al}_{2} \mathrm{O}_{3}(\%)$ & $\mathrm{Fe}_{2} \mathrm{O}_{3}(\%)$ & $\mathrm{Tio}_{2}(\%)$ & $\mathrm{CaO}(\%)$ & $\mathrm{MgO}(\%)$ & $\mathrm{K}_{2} \mathrm{O}(\%)$ & $\mathrm{Na}_{2} \mathrm{O}(\%)$ \\
\hline 55.06 & 44.12 & 0.76 & 0.24 & 0.17 & 0.06 & 0.55 & 0.06 \\
\hline
\end{tabular}

\subsection{Test method}

The recommended gradation of cement stabilized graded crushed stone in JTG / T F20 2015 ' Highway Pavement Construction Technical Rules' is adopted. Five schemes are designed according to the C-B-1 gradation required by highways and first-class highways : the original base mixture ( G0 ), and the metakaolin is replaced by $1 \%, 3 \%$ and $5 \%$ of the total mass of the mixture to replace the fine aggregate in the mixture, respectively represented by G1, G3 and G5. In addition, the metakaolin of $1 \%$ of the total mass of the mixture is used to replace $0.075 \mathrm{~mm}$ ultrafine aggregate ( G1X ) in the mixture, and the cement content is $3.5 \%$. The compaction test, unconfined compressive strength test and dry shrinkage test are carried out in accordance with the ' Test Specification for Inorganic Bond Stabilized Materials in Highway Engineering ( JTG E51-2009 ) '.

\section{Test result analysis}

\subsection{Physical and mechanical properties}

The optimum water content, maximum dry density and $7 \mathrm{~d}$ strength of each mixture were obtained through compaction test and unconfined compressive strength test. The test results are shown in Table 2.

Table 2. Physical and mechanical properties of cement stabilized recycled aggregate base mixture with different metakaolin content.

\begin{tabular}{|c|c|c|c|c|c|}
\hline & G0 & G1 & G3 & G5 & G1X \\
\hline Optimum moisture content (\%) & 11.198 & 10.480 & 10.784 & 11.027 & 12.640 \\
\hline Maximum dry density & 2.094 & 2.132 & 2.121 & 2.103 & 2.159 \\
\hline $\begin{array}{c}\text { 7d unconfined compression } \\
\text { strength (Mpa) }\end{array}$ & 5.02 & 5.20 & 5.35 & 4.84 & 5.31 \\
\hline
\end{tabular}

It can be seen from Table 2 that the change of the optimum moisture content of the base mixture is related to the content of metakaolin added. Using metakaolin instead of fine aggregate in base mixture can reduce the optimum moisture content. After adding $1 \%$ metakaolin, the decrease was the largest, and the optimal moisture content decreased from $11.198 \%$ of G0 to $10.499 \%$ of G1, with a decrease of $6.41 \%$. However, the optimum moisture content of G1X increased by $12.9 \%$ than that of G0 after $1 \%$ metakaolin was 
replaced by superfine aggregate in the mixture. In addition, after adding a small amount of metakaolin to the base mixture, the maximum dry density of the mixture increased slightly, basically between $2.10 \mathrm{~g} / \mathrm{cm} 3$ and $2.16 \mathrm{~g} / \mathrm{cm} 3$, with an increase of $0.5 \%-3.3 \%$.

It can be seen from Table 2 that the $7 \mathrm{~d}$ unconfined compressive strength of the base mixture is related to the content of metakaolin added. The $7 \mathrm{~d}$ unconfined compressive strength of G1, G3 and G1X were higher than that of G0, with the increase of 3.6 \%, $6.6 \%$ and $5.8 \%$, respectively. When $5 \%$ metakaolin was added to the base mixture, the $7 \mathrm{~d}$ unconfined compressive strength of G5 decreased by $0.18 \mathrm{MPa}$, which was $3.4 \%$ lower than that of G0. It is proved that adding a small amount of metakaolin can improve the $7 \mathrm{~d}$ unconfined compressive strength of the base mixture, which is mainly because the strength of the base mixture is related to its composition and pore structure characteristics. Metakaolin belongs to mineral admixtures and has activity. The main active components are alumina and silica, accounting for about $90 \%$. The size of active components is small, both below $5 \mathrm{um}$. Therefore, they have good volcanic ash effect when used as mineral admixtures. Metakaolin can exert pozzolanic effect at the early stage of cement hydration, thereby reducing the content of calcium hydroxide crystal in hydration products and increasing the content of C-S-H gel. At the same time, pozzolanic effect can reduce the calcium-silicon ratio in the gel, thereby improving the density of hydration products. In addition, metakaolin can play a size effect in the mixture, generate solid particles and dense accumulation, so as to refine the pore size distribution of the mixture and improve the compressive strength of the mixture. Due to the existence of a large number of glassy alumina in metakaolin, the volcanic ash effect is more intense in the early stage, which has a good promoting effect on early strength.

\subsection{Drying shrinkage}

According to the previous research results, the shrinkage performance of cement stabilized base mixture has a certain relationship with the optimum moisture content. According to the compaction test results, G1, which is the most economical and has the best effect on reducing the optimum moisture content, is selected for the dry shrinkage test in this section, and the results are compared with those of G0. The test results are shown in Figs. 3.
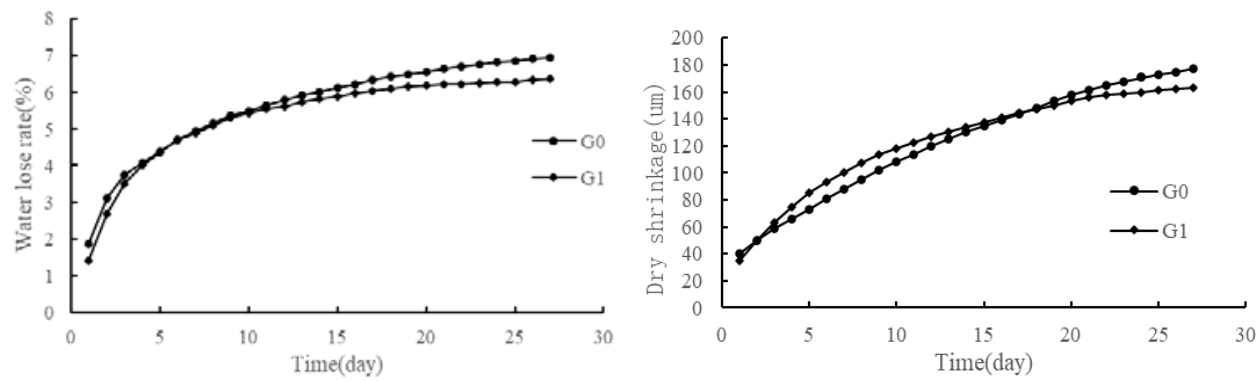

Fig. 3. Water loss rate and dry shrinkage change over time.

It can be seen from Fig. 3 that the water loss rates of the two base mixtures increase with time, and the water loss rate is faster in $1-7$ days, and slightly slower in $7-14$ days. In the late stage of water loss, namely after 14 days, the water loss rate remained basically stable. After adding $1 \%$ metakaolin, the variation trend of water loss rate of G1 with time was almost consistent with that of G0. However, the $27 \mathrm{~d}$ total water loss rate of G1 was $6.36 \%$, which was $8.6 \%$ lower than that of G0. 
The change trend of dry shrinkage of the two kinds of base mixtures with time is basically the same. The dry shrinkage increases with time, and the growth is fast in the early stage, and gradually decreases in the late stage. After adding $1 \%$ metakaolin, the dry shrinkage of G1 was greater than that of G0 in the first 14 days, but the total dry shrinkage of 27 days was less than that of G0. The dry weight of G1 was reduced by 14um than that of $\mathrm{G} 0$, and the reduction ratio was $7.9 \%$. This is because the dry shrinkage of the base mixture is usually caused by the water loss of the capillary pores and gel pores smaller than $50 \mathrm{~nm}$. Metakaolin can reduce the content of capillary pores in the mixture and increase the content of gel pores. The role of metakaolin in refining the pore size can reduce the total dry shrinkage of the base mixture. In addition, metakaolin can also promote the hydration process of cement, thereby increasing the drying shrinkage caused by hydration reaction, which has a negative impact on reducing the early drying shrinkage of base mixture. Therefore, the influence of metakaolin on dry shrinkage of base mixture is caused by the combined action of the above two parts. Metakaolin has large particle size and contains a large number of active substances such as alumina, which can promote the formation of $\mathrm{AFt}$ and AFm in volcanic ash reaction and further inhibit the shrinkage of base mixture.

\section{Summary}

(1) Adding a small amount of metakaolin can reduce the optimum water content of cement stabilized recycled aggregate base mixture and improve the maximum dry density of the mixture.

(2) The unconfined compressive strength of cement stabilized recycled aggregate base mixture can be significantly improved when the dosage of metakaolin is $1 \% \sim 3 \%$, but it is unfavorable to the strength growth when the dosage is increased to $5 \%$.

(3) The water loss rate and dry shrinkage of cement stabilized recycled aggregate base mixture with metakaolin increase with time, which are higher than those without metakaolin in the early stage, but lower in the later stage, and the total dry shrinkage is smaller. Adding $1 \%$ kaolin can reduce the dry shrinkage of cement stabilized recycled aggregate base mixture.

\section{References}

1. Lingqing Liu. Performance and design of cement stabilized recycled aggregate[D]. Chang'an University(2014)

2. Yiwu Shen. Key technology of dry shrinkage performance of recycled concrete road base materials [D]. Suzhou University of Science and Technology(2020)

3. Zenghua Zhou.Feasibility analysis of construction waste recycling in road construction[J]. Engineering and Construction, 23,624-626(2009)

4. Tianxiang Cui. Experimental Study on Performance of High Performance Concrete with Metakaolin[D]. Central South University of Forestry and Technology(2021)

5. Qiang Yu,Junjie Zeng,Zhihong Fan. Comparative analysis of the influence of metakaolin and silica fume on concrete performance[J]. Bulletin of The Chinese Ceramic Society, 33,3135-3139(2014)

6. Chong Wang,Xianwen Wu,He Huang. Performance comparison of high strength concrete prepared by metakaolinite and silica fume[J]. Journal of Chongqing University, 30,65-69(2007) 